\title{
Effect of Storage Duration on Water Activity of Green Gram Stored in Hermetic and Other Bags
}

\author{
Asha Kumari and Mukesh Shrivastava*
}

Department of Processing and Food Engineering, College of Agricultural Engineering, Dr. Rajendra Prasad Central Agricultural University, Pusa (Samastipur) - 848 125, Bihar, India

*Corresponding author

\section{A B S T R A C T}

\section{Keywords}

Green gram, Hermetic bag, Jute bag, Plastic bag, Polythene bag, Treated, Untreated, Storage Duration, Water activity, UNIANOVA

Article Info

Accepted: 06 June 2018 Available Online: 10 July 2018
Green gram (Vigna radiate) grains were procured from local market, cleaned and graded by two screen cleaner-cum-grader. Storage study was conducted by storing large sized green gram grains in 4 types of bags (jute, plastic, polythene, hermetic) without and with treatment (aluminium phosphide tablets) at 3 different initial moisture contents (12.34, 14.07, $16.04 \%$ w.b.). Total 21 such bags having different treatment combinations were kept in laboratory for 33 weeks. Daily observation of ambient temperature and relative humidity was taken throughout the study period. Weekly observations of moisture content were recorded for 27 (jute bags) to 33 weeks (hermetic bags). It was observed that water activity goes on increasing with advancement of storage duration across all 21 experimental combinations. The overall variation range for water activity was 0.551 to 0.989. Variation was more in case of untreated samples as compared to treated samples. Hermetic bags stored green gram was found better with minimum water activity uptake even after 33 weeks of storage duration. Statistical analysis through UNIANOVA revealed that treatment emerged as most important independent variable to affect water activity. The interaction of bags*trt*imc*week significantly affected water activity. Hence the hermetic bag could be recommended for storing green gram safely for longer duration without affecting its quality.

\section{Introduction}

Agriculture is the backbone of Indian economy contributing $13.7 \%$ of its total GDP and employing around $55 \%$ of the total working population in India. Around 65\% of India's population is dependent upon agriculture and allied sectors. Various cereals (wheat, rice etc.), pulses (pigeon pea, gram etc.) and oilseeds (groundnut, soybean) are produced largely in India. India is the world's largest producer and consumer of pulses accounting about $27 \%$ of the total production and about $30 \%$ of total consumption in world. Total production of pulses in India during the year 2013-14 was 18.5 million tons. In the year 2015-16, the pulse production in Bihar has been estimated as 7.35 lakh tons, out of 
which green gram shared 1.558 lakh tons. Post-harvest Food Loss (PHL) is defined as measurable qualitative and quantitative food loss along the supply chain, starting at the time of harvest till its consumption or other end uses. Post harvest losses are due to poor production practices, poor post harvest management practices, lack of grading at farm level, poor packaging, poor transportation, multiple handling, and poor marketing system. Reduction of pre-harvest, harvest and postharvest losses is indeed a complementary means of increasing the food availability. Storage losses are due to high moisture content of the stored material, the storage condition (high relative humidity), erratic climatic condition, absence of primary processing (cleaning and grading) at farm level and lack of storage facility at production catchment. The storage loss in commercial storage of food grains is around 3 to $5 \%$ when storage was done for 8 months (Krishnamurthy, 1975).

A method considered for the prevention of storage losses in airtight storage bags termed as 'airtight storage' or 'hermetic storage' bags. Hermetic storage systems strive to eliminate all exchange of gases between the inside and the outside of a grain storage container/bag. If the gas exchange is low enough, living organisms such as insects within the container/bag will deplete oxygen and produce carbon dioxide until they die or become inactive due to the low oxygen. Hermetic storage bags is a safe, cost-effective storage method that controls insect infestations in addition to preserving the quality of grains, while allowing for pesticide-free, short-term and long-term qualitative and quantitative seed preservation, without refrigeration, maintaining seed vigor and pest control. Storage at low temperature $\left(4^{\circ} \mathrm{C}\right)$ ensures greater safety margins between insect development time and break of dormancy, although hermetic storage, even at ambient temperatures, naturally eliminates insect development altogether. Hermetic storage is capable of maintaining relative humidity that preserves seed moisture and prevents mold growth. Hermetic bags need to be validated for its effectiveness in hermetic storage of food grains under Bihar conditions. In response to requests by farmers, traders and private seed companies to determine the effectiveness of hermetic bags for storage of cereals/pulses, a comparative study on storage behavior of green gram different storage bags was made to assess the qualitative and quantitative loss and to validate the advantages of hermetic bags in green gram storage over the conventional storage bags used in the region.

\section{Materials and Methods}

\section{Sample preparation and treatment}

Fresh and healthy green gram pulse grains were procured from local farmer at Ratwara village of Muzaffarpur district in Bihar. Cleaning and grading of grains was done in two screen seed cleaner-cum-grader using top screen of $4.0 \mathrm{~mm}$ and bottom screen of 2.5 $\mathrm{mm}$ round holes. Total $210 \mathrm{~kg}$ cleaned and graded green gram grains of $2.64 \mathrm{~mm} \varnothing$ size with moisture content of $12.05 \%$ w.b. were available for storage study. Grains were weighed on a digital platform type balance (WENSER) having $150 \mathrm{~kg}$ capacity and 0.01 kg sensitivity.

The fumigant (Aluminium Phosphide) popularly known as sulphas was used for the chemical treatment whose molecular formula is AlF, molecular weight is 57.955 gm.mole $^{-1}$ and density is $2.85 \mathrm{gm} . \mathrm{cm}^{-3}$. Half sulphas tablet weighing $0.93 \mathrm{~g}$ kept inside a piece of muslin cloth was placed in the centre of the bag and bag-mouth was closed by tightly twisting the free portion and then tying it by plastic rope. 


\section{Experimental variables}

\section{Independent variables}

1. Type of : 4 types [Jute (JUT), storage bags Plastic (PLS),

Polythene (PLY), Hermetic (HER)]

2. Initial moisture : 3 levels [IMC1content $12.32 \%, \quad$ IMC2(IMC) \% w. b. $14.04 \%, \quad$ IMC3$16.04 \%$ w.b.]

3. Treatment : 2 levels [Treated chemically (T), Untreated (UT)]

4. Storage : 28 to 34 levels [Jute duration bags -0 to 27 (weeks) weeks, Plastic bags 0 to 29 weeks, Polythene bags 0 to 31 weeks, Hermetic bags 0 to 33 weeks]

\section{Dependent variables}

- Water activity

\section{Observations}

- $\quad$ Ambient temperature ${ }^{\circ} \mathrm{C}$ (Daily)

- $\quad$ Ambient R.H., \% (Daily)

\section{Experimental design}

Factorial - 4 types of bags $\times 2$ types of treatment $\times 3$ levels of $\mathrm{IMC}=24$ Combinations

But the Hermetic bags were used to store samples without any treatment only, so the total combination reduced to 21 as detailed in Table A.

\section{Experimental methodology}

After determining moisture content of cleaned and graded lot of green gram grains as $12.05 \%$ w.b., the whole lot was subdivided in three sub-lots. Required amount of water was added in two sub-lots which were left for tempering for 24 hours to adjust the moisture within the grain heap for getting two more desired levels of moisture contents. The initial moisture content of all three lots was determined again which were found as $12.34 \%, 14.07 \%$, $16.04 \%$ w.b. Then green gram grains were stored in 21 bags as per experimental design. The size of hermetic/polythene bag was $112 \times 61 \mathrm{~cm}$, and of jute/plastic was $83 \times 55 \mathrm{~cm}$ (having capacity of $50 \mathrm{~kg}$ each). For treatment of samples, half tablet $(0.93 \mathrm{~g})$ of sulphas tied in a small piece of muslin cloth was kept in stored grains. The mouth of each bag was tied with the help of plastic rope after evacuating air above the stored grains out of the bag. For observations, samples were drawn from each bag randomly every week. Observations were continued for 27-33 weeks for different bags depending upon the condition of resultant grains.

Water activity is defined as the ratio of the vapour pressure of water in a material (p) to the vapour pressure of pure water $\left(\mathrm{p}_{\mathrm{o}}\right)$ at the same temperature. Relative humidity of air is defined as the ratio of the vapour pressure of air to its saturation vapour pressure. When vapour and temperature equilibrium are obtained, the water activity of the sample is equal to the relative humidity of air surrounding the sample in a sealed measurement chamber. Multiplication of water activity by 100 gives the equilibrium relative humidity (ERH) in percent.

$\mathrm{a}_{\mathrm{w}}=\mathrm{p} / \mathrm{p}_{\mathrm{o}}=\mathrm{ERH}(\%) / 100$

Water activity $\left(\mathrm{a}_{\mathrm{w}}\right)$ is one of the most critical factors in determining quality and safety of the foods you consumed every day. Water activity affects the shelf life, safety, texture, flavour, and smell of foods. Water activity may be the most important factor in controlling spoilage. 
Water activity of green gram was measured during experimentation using water activity meter (ROTRONIC, HygroPalm, AW-DIO) at ambient temperature.

The ambient temperature and relative humidity were recorded by portable digital temperature/relative humidity meter (ZEAL, $\left.0.1^{\circ} \mathrm{C}, 0.1 \%\right)$. Observations were taken on daily basis during entire period of experimental storage in near vicinity of storage bags.

\section{Results and Discussion}

The summarized overall variation in water activity with minimum and maximum values under each experimental combination has been presented in Table 1. It reveals that the water activity of the grain was initially in the range of 0.551 to 0.649 for three initial moisture contents (IMC) which went up in the range of 0.857 to 0.989 after 33 weeks of storage. The highest water activity value was observed as 0.989 for the experimental combination of JUT/UT/IMC3. The water activity of untreated Green gram grains in the jute bag was increased from 0.551 to 0.989 across all IMCs after 27 weeks of storage. Similarly water activity of treated Green gram grains in the jute bag was increased from
0.551 to 0.981 across all IMCs after 27 weeks of storage. The water activity of untreated Green gram grains in hermetic (HER) bag was increased from 0.551 to 0.900 across all IMCs after 33 weeks of storage. The hermetic bags performed better allowing minimum water activity uptake as compared to other types of bags. The elevation in water activity with storage period may due to increase in moisture content owe due to variation in temperature and relative humidity during storage period. These results are in line with results of previous researchers - Mutungi et al.,(2014), Kumari et al.,(2015), Freitas et al.,(2015) and Kumar et al.,(2016) for other grains.

Water activity had a general increasing trend across all experimental combinations with advancement of storage duration (Fig. 1). This may be due to increase in ambient relative humidity and dampness created by the heat of respiration of the grain. Untreated Green gram grains stored in hermetic (HER) bags had lowest water activities at all IMCs as compared to polythene (PLY) bags, plastic (PLS) bags and jute (JUT) bags in that order. Similarly treated grains behaved in the same manner across all combinations. The water activity uptake was lower at IMC1 as compared to IMC3 at all experimental combinations.

Table.A
- $\quad 3 \mathrm{JUT}$ bags $-\mathrm{T}-$ with $\mathrm{IMC}_{1}, \mathrm{IMC}_{2}, \mathrm{IMC}_{3}$
- 3 PLY bags - T - with $\mathrm{IMC}_{1}, \mathrm{IMC}_{2}, \mathrm{IMC}_{3}$
- 3 JUT bags - UT - with $\mathrm{IMC}_{1}, \mathrm{IMC}_{2}$, $\mathrm{IMC}_{3}$
- 3 PLY bags - UT - with $\mathrm{IMC}_{1}, \mathrm{IMC}_{2}$, $\mathrm{IMC}_{3}$
- 3 PLS bags - UT - with $\mathrm{IMC}_{1}, \mathrm{IMC}_{2}$, $\mathrm{IMC}_{3}$
- 3 HER bags - UT - with $\mathrm{IMC}_{1}, \mathrm{IMC}_{2}$, $\mathrm{IMC}_{3}$


Table.1 Summarized overall variation in water activity for all experimental combinations

\begin{tabular}{|c|c|c|}
\hline Treatment Combination & Max.Value (week no) & Min.Value (week no) \\
\hline JUT/T/IMC1 & $0.970(27)$ & $0.551(0)$ \\
\hline JUT/UT/IMC1 & $0.980(27)$ & $0.551(0)$ \\
\hline PLS/T/IMC1 & $0.925(29)$ & $0.551(0)$ \\
\hline PLS/UT/IMC1 & $0.936(29)$ & $0.551(0)$ \\
\hline PLY/T/IMC1 & $0.884(31)$ & $0.551(0)$ \\
\hline PLY/UT/IMC1 & $0.902(31)$ & $0.551(0)$ \\
\hline HER/UT/IMC1 & $0.857(33)$ & $0.551(0)$ \\
\hline JUT/T/IMC2 & $0.979(27)$ & $0.604(0)$ \\
\hline JUT/UT/IMC2 & $0.985(27)$ & $0.604(0)$ \\
\hline PLS/T/IMC2 & $0.938(29)$ & $0.604(0)$ \\
\hline PLS/UT/IMC2 & $0.949(29)$ & $0.604(0)$ \\
\hline PLY/T/IMC2 & $0.900(31)$ & $0.604(0)$ \\
\hline PLY/UT/IMC2 & $0.914(31)$ & $0.604(0)$ \\
\hline HER/UT/IMC2 & $0.878(33)$ & $0.604(0)$ \\
\hline JUT/T/IMC3 & $0.981(27)$ & $0.649(0)$ \\
\hline JUT/UT/IMC3 & $0.989(27)$ & $0.649(0)$ \\
\hline PLS/T/IMC3 & $0.940(29)$ & $0.649(0)$ \\
\hline PLS/UT/IMC3 & $0.952(29)$ & $0.649(0)$ \\
\hline PLY/T/IMC3 & $0.925(31)$ & $0.649(0)$ \\
\hline PLY/UT/IMC3 & $0.943(31)$ & $0.649(0)$ \\
\hline HER/UT/IMC3 & $0.900(33)$ & $0.649(0)$ \\
\hline
\end{tabular}


Table.2 UNIANOVA for effect of independent variables on water activity

\begin{tabular}{|c|c|c|c|c|c|}
\hline Source & Type III Sum & df & Mean Square & $\mathrm{F}$ & Sig. \\
\hline Corrected Model & $144232.839^{\mathrm{a}}$ & 620 & 232.634 & 1.051 & $.234^{\mathrm{ns}}$ \\
\hline Intercept & 1591.111 & 1 & 1591.111 & 7.186 & .007 \\
\hline Bags & 637.865 & 3 & 212.622 & .960 & $.411^{\mathrm{ns}}$ \\
\hline Trt & 228.514 & 1 & 228.514 & 1.032 & $.310^{\mathrm{ns}}$ \\
\hline Imc & 283.296 & 2 & 141.648 & .640 & $.528^{\mathrm{ns}}$ \\
\hline Week & 3868.775 & 32 & 120.899 & .546 & $.982^{\mathrm{ns}}$ \\
\hline bags $* \operatorname{trt}$ & 616.187 & 2 & 308.093 & 1.391 & $.249^{\mathrm{ns}}$ \\
\hline bags $*$ imc & 1391.356 & 6 & 231.893 & 1.047 & $.393^{\mathrm{ns}}$ \\
\hline bags * week & 19379.255 & 84 & 230.705 & 1.042 & $.380^{\mathrm{ns}}$ \\
\hline trt $*$ imc & 514.098 & 2 & 257.049 & 1.161 & $.314^{\mathrm{ns}}$ \\
\hline trt $*$ week & 7772.627 & 30 & 259.088 & 1.170 & $.242^{\mathrm{ns}}$ \\
\hline imc * week & 7725.486 & 64 & 120.711 & .545 & $.999^{\mathrm{ns}}$ \\
\hline bags $* \operatorname{trt} *$ imc & 1127.293 & 4 & 281.823 & 1.273 & $.279^{\mathrm{ns}}$ \\
\hline bags $* \operatorname{trt} *$ week & 15521.577 & 54 & 287.437 & 1.298 & $.075^{\mathrm{ns}}$ \\
\hline bags $*$ imc $*$ week & 38796.265 & 168 & 230.930 & 1.043 & $.347^{\mathrm{ns}}$ \\
\hline $\operatorname{trt} *$ imc $*$ week & 15537.443 & 60 & 258.957 & 1.170 & $.180^{\mathrm{ns}}$ \\
\hline bags $* \operatorname{trt} *$ imc $*$ week & 31024.615 & 108 & 287.265 & 1.297 & .026 \\
\hline Error & 288944.769 & 1305 & 221.414 & & \\
\hline Total & 435194.018 & 1926 & & & \\
\hline Corrected Total & 433177.609 & 1925 & & & \\
\hline \multicolumn{6}{|c|}{ a. $\mathrm{R}$ Squared $=.333($ Adjusted R Squared $=.016)$} \\
\hline
\end{tabular}

\section{Water Activity Meter}

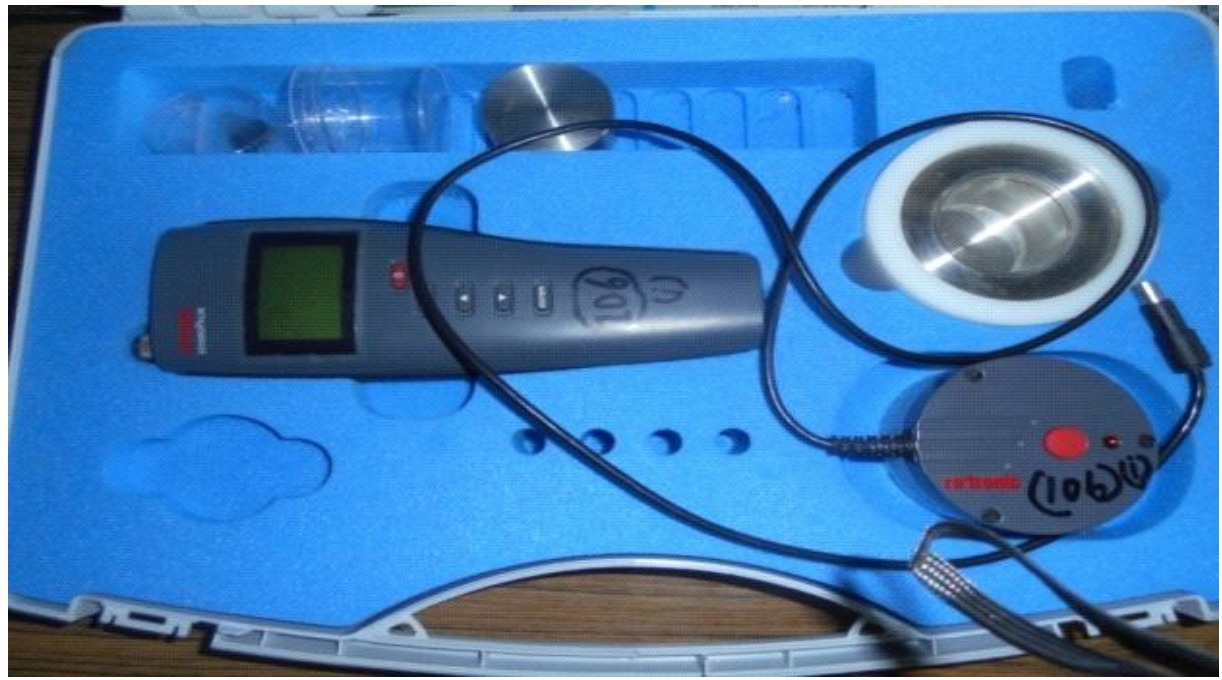

Fig.1 Variation in water activity with storage duration for different bags and treatment at three different initial moisture contents 

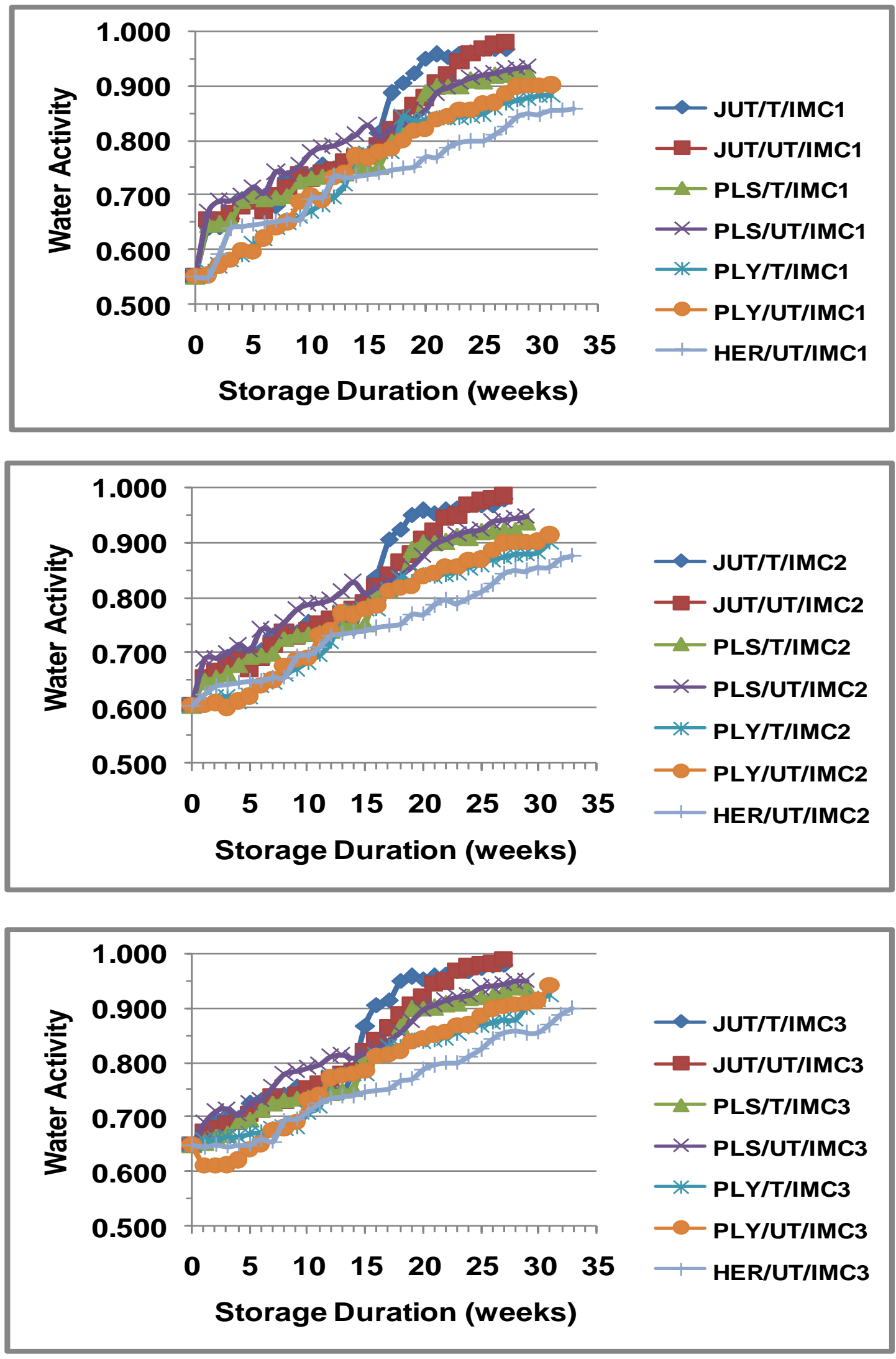
Table 2 shows UNIANOVA for main factors effect and their interaction effect on water activity for the entire experiment. It reveals that all main variables individually and their interaction had a non-significant effect on water activity.

The treatment having highest F-value affected moisture content the most, followed by bags, imc and weeks. Interaction of bags*trt*imc*week was the only interaction affecting water activity significantly.

In conclusion water activity had a general increasing trend across all experimental combinations with advancement of storage duration. This may be due to increase in ambient relative humidity and dampness created by the heat of respiration of the grain. Untreated Green gram grains stored in hermetic (HER) bags had lowest moisture contents at all IMCs as compared to polythene (PLY) bags, plastic (PLS) bags and jute (JUT) bags in that order. Similarly treated grains behaved in the same manner across all combinations. The water activity uptake was lower at IMC1 as compared to IMC3 at all experimental combinations.

The hermetic bags performed better allowing minimum water activity uptake as compared to other types of bags. Hence the hermetic bags could be recommended for storing green gram safely for longer duration without affecting its quality.

\section{References}

Freitas, R. S. Hermetic storage for control of common bean weevil, Acanthoscelidesobtectus. 2016. Journal of Stored Products Research. $66: 1-5$.

Krìshnamurthy, K. 1975. Post-harvest losses in food grains. Bulletin of Grain Technology. 13(1): 33-49.

Kumar, N., Kumar, S., Kumar, V. and Rajak D. 2016. Comparative Study on Storage Behavior of Wheat in Different Storage Bags. B. Tech. project report submitted to College of Agricultural Engineering, RAU, Pusa, Bihar.

Kumari, A. and Shrivastava, M. Storage behavior of green gram (Vigna radiate) in hermetic and other types of storage bags. 2017. Unpublished M. Tech. thesis submitted to Department of Processing and Food Engineering, College of Agricultural Engineering, DrRPCAU, Pusa, Bihar.

Kumari, A., Rajak, D., and Kumar, V. 2015. Comparative Study on Storage Behavior of Food Grain in Different Storage Bags. B. Tech. project report submitted to College of Agricultural Engineering, RAU, Pusa, Bihar.

Mutungi C.M. 2014. Storage of mung bean and pigeon pea grains in hermetic triple-layer bags stop losses caused by Callosobruchusmaculatus. Journal of Stored Products Research. 58:39-47.

\section{How to cite this article:}

Asha Kumari and Mukesh Shrivastava. 2018. Effect of Storage Duration on Water Activity of Green Gram Stored in Hermetic and Other Bags. Int.J.Curr.Microbiol.App.Sci. 7(07): 733-740. doi: https://doi.org/10.20546/ijcmas.2018.707.090 